American J. of Engineering and Applied Sciences 1 (1): 16-23, 2008

ISSN 1941-7020

(C) 2008 Science Publications

\title{
A Study of Thermal Contact using Nonlinear System Identification Models
}

\author{
${ }^{1}$ M.H. Shojaeefard, ${ }^{1}$ K. Goudarzi, ${ }^{2}$ A.R. Noorpoor and ${ }^{2}$ M. Fazelpour \\ ${ }^{1}$ Department of Mechanical Engineering, \\ ${ }^{2}$ Department of Automotive Engineering, \\ Iran University of Science and Technology, Narmak, 16844, Tehran, Iran
}

\begin{abstract}
One interesting application of system identification method is to identify and control the heat transfer from the exhaust valve to the seat to keep away the valve from being damaged. In this study, two co-axial cylindrical specimens are used as exhaust valve and its seat. Using the measured temperatures at different locations of the specimens and with a semi-analytical method, the temperature distribution of the specimens is calculated and consequently, the thermal contact conductance is calculated. By applying the system identification method and having the temperatures at both sides of the contact surface, the temperature transfer function is calculated. With regard to the fact that the thermal contact has nonlinear behavior, two nonlinear black-box models called nonlinear ARX and NLN Hammerstein-Wiener models are taken for accurate estimation. Results show that the NLN Hammerstein-Wiener models with wavelet network nonlinear estimator is the best.
\end{abstract}

Keywords: Identification, nonlinear models, thermal contact conductance, exhaust valve

\section{INTRODUCTION}

Internal combustion engines generate exhaust gases with extremely high temperatures. When these hot gases exit through the exhaust valve, the valve gets high temperature. In order to avoid any damage to the engine, the heat is removed from the exhaust valve and led to the seat when they come into contact with each other during the opening and the closing of the exhaust valve. Furthermore, the exhaust valve temperature distribution and the removed heat have a significant effect on engine performance ${ }^{[1,2]}$.

The Engine Control Unit (ECU) monitors the coolant temperature, engine load, throttle position, engine speed and knock sensor to regulate the fuel and cooling processes. To increase the engine's thermal efficiency, the ECU requires a model that estimates the thermal behavior of the engine cylinder components. The ultimate goal for the researchers is to create a model with higher operating within the cylinder without damaging any components. Therefore a mathematical model is necessary to describe the thermal behavior of the exhaust valve with attention focused on periodic contact resistance $\mathrm{e}^{[1,2]}$.

A theoretical study is made by Howard ${ }^{[3]}$, who considered heat transfer in a mathematical model comprising two identical bars of material of length, 1 , whose longitudinal axes are in line and whose adjacent ends could be brought into contact and separated cyclically. An inverse heat conduction method for determining the periodically time-varying thermal contact conductance between two periodically contacting surfaces is presented by Flach and Ozisik ${ }^{[4]}$. The technique is based on solving two single-region inverse problems for the contact surface temperature and heat flux of each solid. Vick and Ozisik ${ }^{[5]}$ utilized the finite integral transform technique to obtain quasisteady-state solutions for the problem of two periodically contacting finite regions with imperfect thermal contact at the interface. This study focused on the effects of contact duration, thermal contact conductance, thermal conductivity and thermal diffusivity on the temperature distribution across two contacting surfaces. Moses and Johnson ${ }^{[6]}$ experimentally examined the problem of periodically contacting similar metal surfaces and obtained results that are comparable in both form and magnitude to those of Vick and Ozisik. Moses and Johnson ${ }^{[7]}$ also experimentally examined the approach to the quasisteady-state condition for similar metallic surfaces in periodic contact, focusing on the behavior of the thermal contact conductance during the contact portion of a cycle and on the number of cycles required to reach a quasi-steady state condition. The experimentally

Corresponding Author: M. Fazelpour, Department of Automotive Engineering, Iran University of Science and Technology, Narmak, 16844, Tehran, Iran 
obtained temperature distributions from Moses and Johnson also are examined by Beck as an example of a parameter and function estimation technique for the inverse heat conduction problem. Dodd and Moses ${ }^{[8]}$ extended this set of experiments to consider periodic contacts between aluminum and stainless steel. Results for this single case of periodic contact between dissimilar metals indicated that the same transient behavior of the thermal contact conductance is observed for all metal pairs.

In internal combustion engine, Huang and $\mathrm{Ju}^{[9]}$ employed the conjugate gradient method to solve the inverse problem and determine the periodic thermal contact conductance as a function of time between the exhaust valve and seat. Couedel et al..$^{[10]}$ conducted an experimental study, which measured in situ the temperature field of an actual valve-seat configuration under periodic contact. Their experimental parameters included periodic frequencies that ranged between 5 and $25 \mathrm{~Hz}$, which corresponds to engine speed between 600 and $3000 \mathrm{rpm}$. The results from experimental setup indicated that the thermal contact conductance is highly dependent on the rotational frequency of the internal combustion engine and that the mean (time-averaged) and periodic temperature field can be measured by the use of an integrating voltmeter and some extremely fast instrumentation. In addition, the thermocouples must be positioned close to the valve-seat interface to obtain efficient measurement of the oscillating temperature fields. Shojaeefard et al..$^{[2]}$ used a new method as system identification to estimate the valve temperature based on seat temperature.

Although significant progress has been made to estimate the heat transfer (thermal contact conductance) between exhaust valve and its seat and the exhaust valve temperature, we are still far from coherent, calculated and accurate temperature distribution of the exhaust valve. Note that all researchers have investigated this study using two co-axial cylindrical specimens. Thus, the obtained results are extremely useful as a baseline to investigate the thermal contact problem in a complex exhaust valve of internal combustion engine.

The main challenge in the measurement of the interface temperature and the calculation of heat transfer from the exhaust valve into its seat is that simulation of the thermocouple is very difficult at the interface near the valve. Due to high temperature of the valve and high motion, strong noise is produced. In this case, the system identification method is found to be the best method that can meet our need.

System identification is the process of developing or improving a mathematical model of a physical system using experimental data. System identification is especially useful for modeling systems that you cannot easily represent in terms of first principles. Therefore, the objective of this study is to estimate the temperature of exhaust valve, the transient thermal contact conductance or heat transfer in the contact surfaces between the exhaust valve and its seat using nonlinear models of system identification.

\section{ESTIMATION PROCEDURE}

The purpose of this study is to estimate the temperatures at contact surface of two cylindrical specimens using the system identification method and then calculating the transient thermal contact conductance, to calculate the heat transfer at contact surface in transient process. In this case, the heat flux is known at the boundary. The ultimate goal and the extension of this work are to apply these results to internal combustion engines. The measurement and estimation of the exhaust valve temperature and thermal contact conductance is extremely difficult in internal combustion engines for thermal management. A computational model can be created by finding transfer function using the system identification method. By applying the contact surface temperature of the seat as input, the contact surface temperature of exhaust valve can be estimated as output with high accuracy. Accordingly, by applying the seat temperature as input, the thermal contact conductance can be determined with high accuracy.

To accomplish this, an experimental apparatus is designed and developed to achieve the objective. To model the surface temperature, thermal contact conductance and heat flux values accurately, the spatial measurements must be closed to the contact surfaces since the transient effects are not accounted for by extrapolation method. The minimum distance between temperature sensor and the contact surface is limited by manufacturing limitations. Also, care must be taken not to disturb the surface characteristics by installing the sensor too close to the surface. Due to rapid and significant number of contacts, the temperature sensor can not be mounted close to the contact surfaces ${ }^{[9]}$. Consequently, an improved method (system identification) is needed to estimate the instantaneous thermal contact conductance is needed to detect fast periodic variation at the contact surface conditions ${ }^{[11]}$.

\section{MEASUREMENT PROCEDURE}

The experimental apparatus shown in Fig. 1 consists of two specimens with one of the non- 
Am. J. Engg. \& Applied Sci., 1 (1): 16-23, 2008

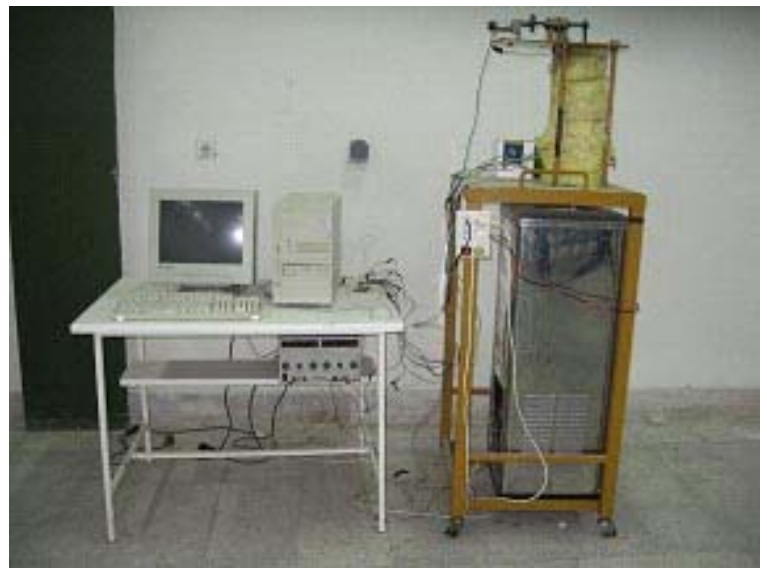

Fig. 1a: Test setup

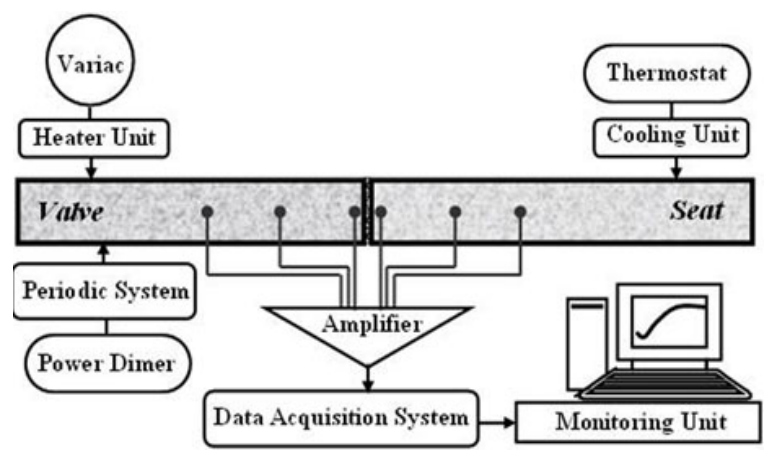

Fig. 1b: Schematic diagram of the apparatus

contacting ends held at a fixed temperature controlled by an ice-water reservoir. The other non-contacting ends held at constant heat flux using an electric heater. The two specimens are suspended by a spring and are free to slide along the two Teflon sleeves to reduce friction and binding at the sliding contact. The Teflon is cut to allow thermocouple to access and move freely in a vertical direction as the surfaces come in and out of contact. The adjacent ends are brought into contact and are separated cyclically. This approach of a camshaft is capable to change various rotational velocities by a selectable speed DC electro-motor, which is located above the upper specimen.

The contact surfaces are clean. On the other hand, the contact surfaces are free of coatings or surface oxidation. Two K-type thermocouples are located on the centerline of each specimen at $2.0 \mathrm{~cm}$ intervals for $4.0 \mathrm{~cm}$ of each specimen adjacent to the contact surface. One additional K-type thermocouple is located on the specimen centerline at $0.05 \mathrm{~cm}$ from the contact surface. These thermocoupleare selected because the range of measurement of the K-type thermocouple is
Table 1: Measured temperatures

\begin{tabular}{lccll}
\hline Time $(\mathrm{min})$ & $\mathrm{TCL}\left({ }^{\circ} \mathrm{C}\right)$ & $\mathrm{T}_{\text {surf }}\left({ }^{\circ} \mathrm{C}\right)$ & $\Delta \mathrm{T}\left({ }^{\circ} \mathrm{C}\right)$ & $\Delta \mathrm{T} / \mathrm{TCL} \times 100$ \\
\hline 20 & 41.3 & 40.4 & 0.9 & 2.18 \\
40 & 156.1 & 153.6 & 2.5 & 1.60 \\
60 & 208.9 & 205.7 & 3.2 & 1.53 \\
80 & 224.2 & 221.9 & 2.3 & 1.02 \\
100 & 275.9 & 271.1 & 4.8 & 1.74 \\
\hline
\end{tabular}

wider and the percentage of its error is less than the other such as T-type thermocouple. In this transient heat transfer at the start of experiment, the hot specimen is heated by an electrical heater (installed at the end of specimen), then the cold specimen starting to warm up by the hot specimen until it reaches steady state condition. During the experiment, we used the variable transformer device to control the heating power of electric heater. The generated noises in experiment are due to environment factors and apparatus such as thermocouples, A/D board, electric current, etc. The data acquisition system includes an Intel PC/Pentium II computer, a monolithic thermocouple amplifier with cold junction compensation (AD594A with 8 terminals) and a signal DC power supply. AD544A board can amplify 10 mvolt analog signals up to +5 to \pm 15 Volts and multiplex 8 differential analog signals to one $\mathrm{A} / \mathrm{D}$ input channel. The data-sampling program is written using Borland $\mathrm{C}$ Programming language on the windows platform.

The heat transfer through the specimens is assumed to be one-dimensional by neglecting the transverse heat transfer and perfect insulation of the specimens. Initial results indicated that, the heat transfer down the specimen was one dimensional. Some of these temperature measurements are given in table 1 for the case of measurements at a distance of $2.0 \mathrm{~cm}$ from the contact surface. At this location on the test specimen, it is seen that the maximum difference between the center line temperature (TCL) and the surface temperature $\left(\mathrm{T}_{\text {surf }}\right)$ is $4.8\left({ }^{\circ} \mathrm{C}\right)$ on the heated specimen. This difference represents up to $1.74 \%$ of any single temperature measurement used in the computation. Therefore, the heat flow in the test specimen is nearly one-dimensional and the radial conduction heat losses are negligible.

The test specimens are cylindrical in shape with a diameter of $0.8 \mathrm{~cm}$ and a length of $20 \mathrm{~cm}$. The holes are drilled perpendicular to each specimen's axis of symmetry. They are located on the center line of each specimen. The surfaces of the cylindrical test specimens are machined in order to obtain surfaces having small roughness about $4.7 \mu \mathrm{m}$ for steel. Thermophysical properties of specimens are shown in Table 2 at $300 \mathrm{~K}$. It should be noted that with increasing the temperature to $800 \mathrm{~K}$, these properties do not vary significantly. 
Am. J. Engg. \& Applied Sci., 1 (1): 16-23, 2008

Table 2: Properties of specimens at $300 \mathrm{~K}$

\begin{tabular}{ll}
\hline Material & Steel \\
\hline Conductivity $\left[\mathrm{W} / \mathrm{m}^{2} \cdot \mathrm{K}\right]$ & 37.7 \\
Density $\left[\mathrm{kg} / \mathrm{m}^{3}\right]$ & 7822 \\
Specific heat $[\mathrm{J} / \mathrm{kg} \cdot \mathrm{K}]$ & 444 \\
Surface roughness $(\mu \mathrm{m})$ & 4.7 \\
Length $(\mathrm{m})$ & 0.20 \\
Reservoir temperature $\left({ }^{\circ} \mathrm{C}\right)$ & 0.0 \\
\hline
\end{tabular}

Thus, properties of specimens at $300 \mathrm{~K}$ are used for calculations.

The temperatures obtained from thermocouples, which is located in each specimen, are used to estimate the thermal contact conductance and heat flux at the interface. It is assumed that the temperature drop on both contact surfaces of the specimens (Fig. 1) is defined by:

$$
\Delta \mathrm{T}_{\mathrm{C}}=\mathrm{T}_{\mathrm{C} 1}-\mathrm{T}_{\mathrm{C} 2} \quad(\mathrm{~K})
$$

Thus, the thermal contact conductance is determined using the following equation:

$$
\mathrm{h}=\mathrm{q} / \Delta \mathrm{T}_{\mathrm{C}} \quad\left(\mathrm{W} \mathrm{\textrm {m } ^ { - 2 } \mathrm { K } )}\right.
$$

where, $\mathrm{q}$ is the heat flux through contact surface. $T_{\mathrm{c} 1}$ and $T_{\mathrm{c} 2}$ are the temperatures of contact surfaces and they are estimated by the nonlinear models of system identification method.

The transient heat flux values can be calculated using the temperature gradient and the thermal conductivity of the heat flux meter material. Fourier's law of heat conduction is used to determine the thermal conductivity of the test specimens from the measured heat flux and the known specimen dimensions. The top heat flux meter gives the heat supplied to the test specimen and the bottom heat flux meter gives the heat removed from the test specimen. It is observed that the heat flux in the top flux meter is more than that in the bottom flux meter. This is due to the radiation from the specimen. Therefore, the average heat flux value across the contact surface is used for calculations ${ }^{[12]}$.

The thermal power of heater is about $300 \mathrm{~W}$. For these experiments, the specimens are held together under constant pressure. The mean interface pressure is approximately equal to $50 \mathrm{kPa}$. Therefore, using the obtained experiments data and system identification method, the transfer function can be identified to predict the contact surface temperatures and calculate the thermal contact conductance.

\section{IDENTIFICATION METHOD}

Since the details of the method have already been documented $^{[2]}$, only a brief presentation of the notation

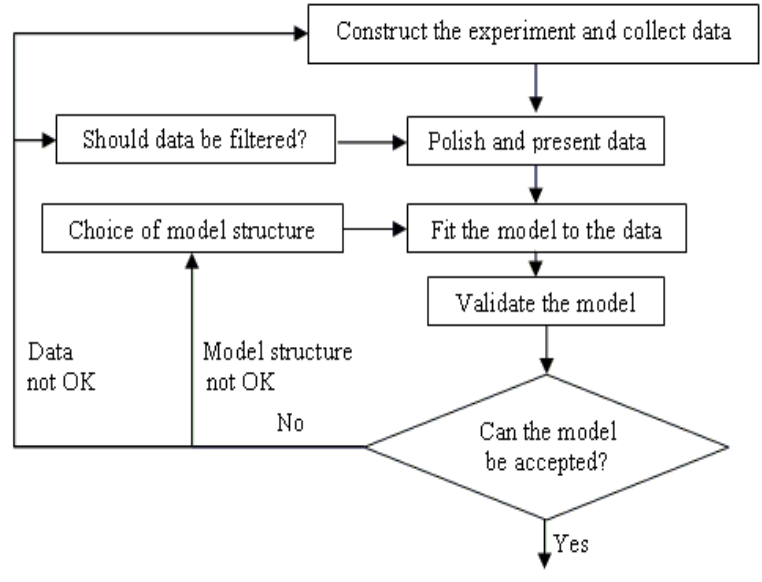

Fig. 2: System identification flowchart

is given here in order to provide the starting point for the present extended analysis.

Concept: System identification is the process of developing or improving a mathematical model of a physical system using experimental data. System identification is especially useful for modeling systems that you cannot easily represent in terms of first principles. This is accomplished by adjusting parameters within a given model until the result matches relatively well with the measured data. Model validation can be carried out by using a separate set of data, which differs from estimating data, to evaluate the model's properties and for validation purpose. The procedure to model a dynamical system is shown in Fig. 2.

Shojaefard and Noorpoor ${ }^{[2,12]}$ analytically estimated the temperature of contact surfaces with system identification method. They only used the linear models that comprised the auto regressive (ARX) and the auto regressive moving average (ARMAX) models based on different equations and all types of linear state-space models. They concluded that the ARMAX model matches rather well.

The thermal contact problems such as thermal contact between exhaust valve and its seat has nonlinear behavior. To capture the significant dynamics of this kind of physical system, nonlinear models are used. In this paper, two nonlinear black-box models including nonlinear ARX and Hammerstein-Wiener models for accurate estimation are applied.

Models structure: For parametric models, the model structure should be specified. If inputs, outputs and disturbances are $\mathrm{u}, \mathrm{y}$ and e, respectively, their relationship can be shown in Fig. 3. 
Am. J. Engg. \& Applied Sci., 1 (1): 16-23, 2008

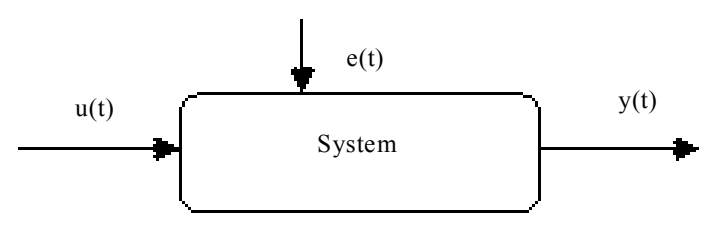

Fig. 3: Dynamic system

Note that disturbance may be due to corrupted input-output data and normally is entirely unpredictable. They are swept sine and white noise. Note that the white noise is a combination of different frequencies.

All nonlinear dynamic input/output models can be written in the form ${ }^{[14]}$ :

$$
\mathrm{y}(\mathrm{k})=\mathrm{F}(\mathrm{u}(\mathrm{k}))
$$

where, $\mathrm{F}$ is a nonlinear regression function and the regression vector, $\mathrm{u}(\mathrm{k})$ can contain previous and possibly current process inputs, previous process or model outputs and previous prediction errors.

Nonlinear ARX structure: The nonlinear ARX structure models dynamic systems using a parallel combination of nonlinear and linear blocks (Fig. 4). The nonlinear and linear functions are expressed in terms of variables called regressors, which are functions of measured input-output data. The predicted output $y(t)$ of a nonlinear model at time $t$ is given by the following general equation ${ }^{[14]}$ :

$$
y(t)=F(x(t))
$$

where, $\mathrm{x}(\mathrm{t})$ represents the regressors. $\mathrm{F}$ is a nonlinear regression function, which is approximated by the nonlinearity estimators. The function $\mathrm{F}$ can include both linear and nonlinear functions of $\mathrm{x}(\mathrm{t})$. We can specify which regressors to use inputs to the nonlinear block. The following equation provides a general description of F:

$$
F(x)=\sum_{k=1}^{d} \alpha_{k} \kappa\left(\beta_{k}\left(x-\gamma_{k}\right)\right)
$$

where, $\kappa$ is the unit nonlinear function, $d$ is the number of nonlinearity units and $\alpha_{\mathrm{k}}, \beta_{\mathrm{k}}$ and $\gamma_{\mathrm{k}}$ are the parameters of the nonlinearity estimator. The model orders $n_{a}, n_{b}$ and $n_{c}$ must specify for computing standard regressors.

Hammerstein-wiener structure: The HammersteinWiener structure models dynamic systems using up to

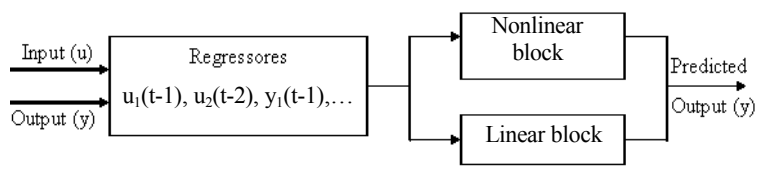

Fig. 4: Nonlinear ARX model

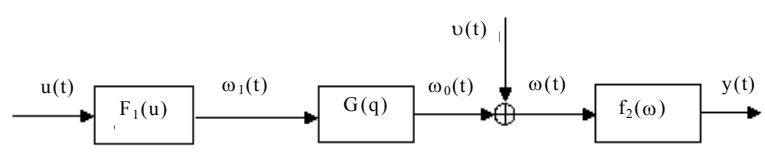

Fig. 5: NLN hammerstein-wiener model

two static nonlinear blocks in series with a linear block (Fig. 5). In a process control environment, this model can be motivated by considering that the input nonlinear block $f_{1}(u)$ represents actuator nonlinearity and the output nonlinear block $\mathrm{f}_{1}(\mathrm{u})$ represents process nonlinearity. Mathematically, because the model includes both the Hammerstein model and the Wiener $\operatorname{model}^{[13,14]}$ as its special cases, it will approximate nonlinear systems better than either of these two models. Note that the disturbance $\mathrm{e}(\mathrm{t})$ enters the process before the output nonlinearity.

The equations that describe the NLN model in Fig. 5 are:

$$
\begin{aligned}
& \omega(\mathrm{t})=\mathrm{F}(\mathrm{u}(\mathrm{t})) \\
& \mathrm{x}(\mathrm{t})=\frac{\mathrm{B}(\mathrm{q})}{\mathrm{F}(\mathrm{q})} \omega(\mathrm{t}) \\
& \mathrm{y}(\mathrm{t})=\mathrm{h}(\mathrm{x}(\mathrm{t}))
\end{aligned}
$$

where, $u(t)$ and $y(t)$ are the inputs and outputs for the system, respectively. $\mathrm{F}$ and $\mathrm{h}$ are nonlinear functions corresponding to the input and output nonlinearities, respectively. $w(t)$ and $x(t)$ are internal variables. $w(t)$ has the same dimension as $\mathrm{u}(\mathrm{t})$. $\mathrm{x}(\mathrm{t})$ has the same dimension as $\mathrm{y}(\mathrm{t})$. $\mathrm{q}$ is the shift operator and $\mathrm{B}(\mathrm{q})$ and $\mathrm{F}(\mathrm{q})$ in the linear dynamic block are polynomials in the backward shift operator, as described in definition of polynomial models.

The nonlinear functions will be parameterized using cubic splines and the linear block with the disturbance will be parameterized using a Box-Jenkins model ${ }^{[14]}$.

\section{RESULTS AND DISCUSSION}

In this research, we carry out this procedure for estimating thermal contact conductance using nonlinear models. 


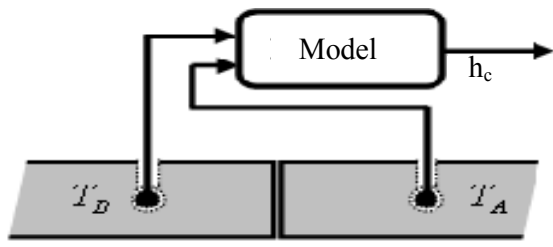

Fig. 6: The system with two-input and two-output for estimating $\mathrm{h}_{\mathrm{c}}$
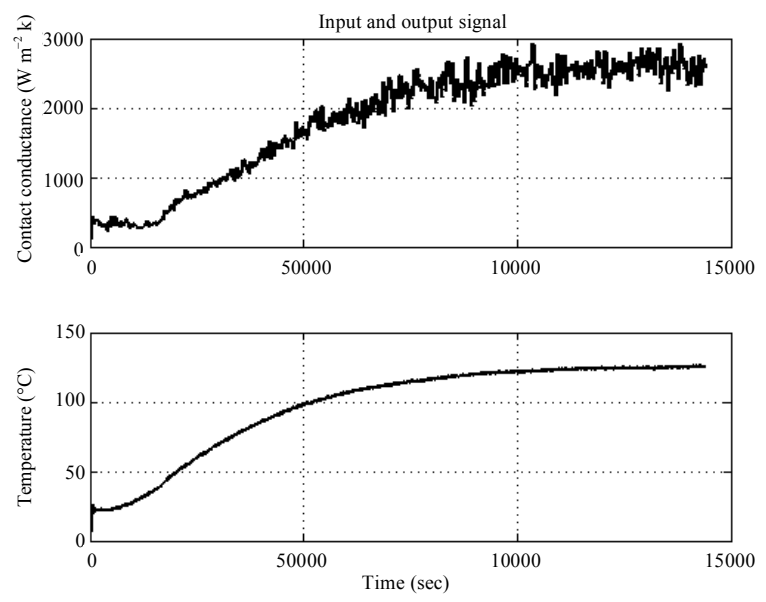

Fig. 7a: Input 1 and output signal
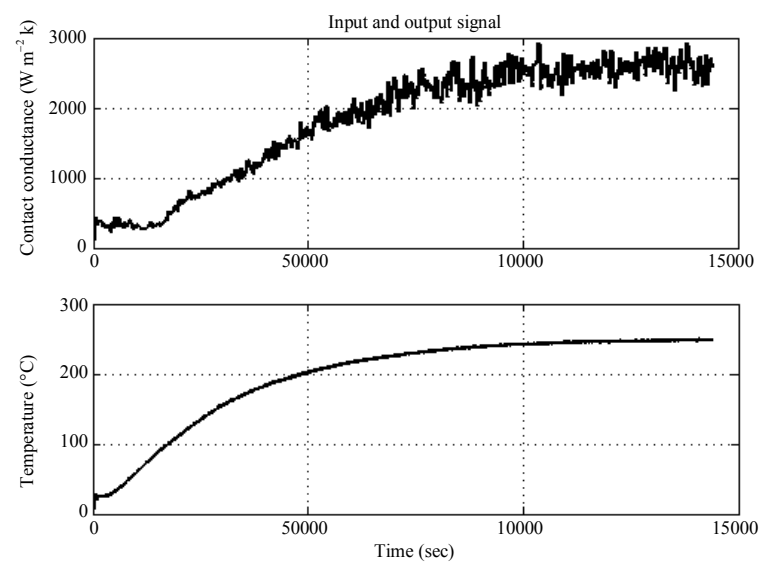

Fig. 7b: Input 2 and output signal

Two temperatures away from contact surfaces as inputs and thermal contact conductance as output are considered, their relationship can be shown in Fig. 6 .

In Fig. 6, $T_{A}$ and $T_{B}$ as input signals are instantaneous temperatures away from contact surfaces of $A$ and $B$ specimens respectively, $h_{c}$ as output signal is time varying thermal contact conductance (Fig. 6). Also, the input and output signal plots for choosing best model are shown in Fig. 7.

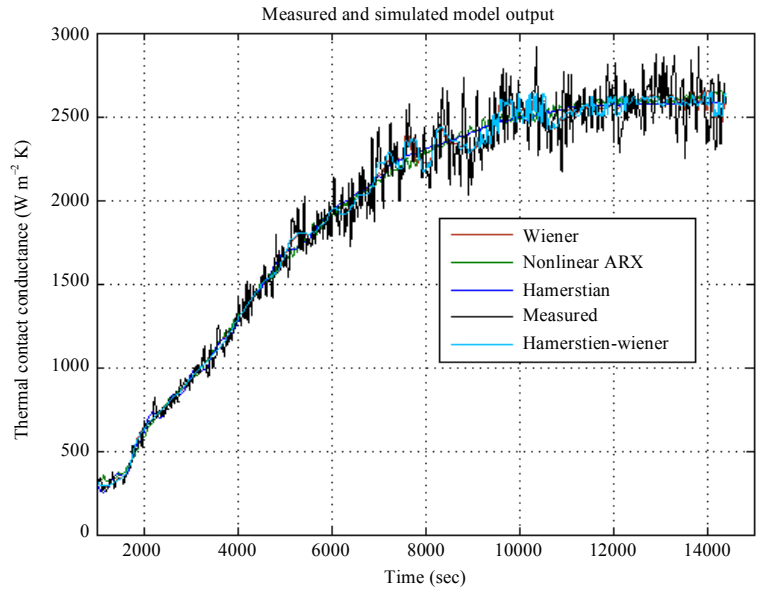

Fig. 8a: Comparisons between several different models for estimation thermal contact conductance

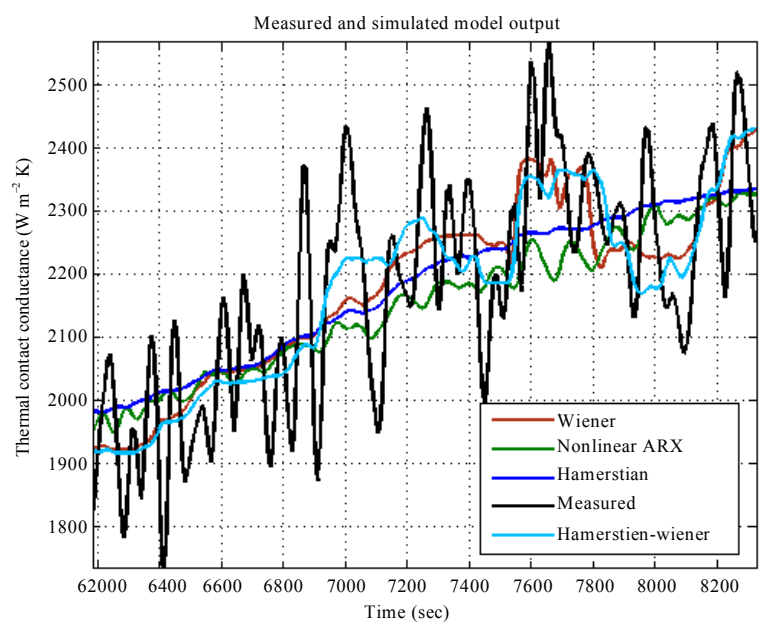

Fig. 8b: Comparisons between several different models for estimation thermal contact conductance

Table 3: Models properties and comparison between the measured and estimated results

\begin{tabular}{llll}
\hline Model & Loss function & FPE & Best fit \% \\
\hline Nonlinear ARX & 544.18 & 585.1 & 86.08 \\
Hammerstein & 12066.2 & $1.262 \times 10^{4}$ & 86.52 \\
Wiener & $1.09 \times 10^{4}$ & $1.129 \times 10^{4}$ & 87.65 \\
Hammerstein-wiener & 9825 & $1.129 \times 10^{4}$ & 87.84 \\
\hline
\end{tabular}

Thermal contact conductance is obtained from nonlinear models in comparison with results of other researchers shown in Fig. 8. Table 3 shows model properties such as loss function, FPE and the percentage of the difference between the model structure and measured data.

According to Table 3, in comparison between the percentage of the difference of the model structures and 
Am. J. Engg. \& Applied Sci., 1 (1): 16-23, 2008

Table 4: Comparison of the model validation (the system with twoinput and one-output)

\begin{tabular}{ll}
\hline Input signal & $\begin{array}{l}\text { The percentage of the output that the } \\
\text { model reproduces (Best fit \%) }\end{array}$ \\
\hline Estimation data $\left(\mathrm{q}_{1}=300 \mathrm{~W}\right)$ & 87.19 \\
Validation data $\left(\mathrm{q}_{2}=400 \mathrm{~W}\right)$ & 86.37 \\
\hline
\end{tabular}

measured data, the Hammerstein-Wiener model has best fit with $87.84 \%$ and the nonlinear ARX model has lowest fit with $86.08 \%$ between the measured and estimated results. It is clear that the difference between the percentages of the different models is not very high, therefore, we can use all the above-mentioned models for estimating surface temperatures.

Finally, the Hammerstein-Wiener model with Wavelet Network nonlinearity estimator is chosen. According to the linear block, orders B, F and the first and second input delays of the linear model are $n_{b}=2$, $\mathrm{n}_{\mathrm{f}}=3, \mathrm{n}_{\mathrm{k} 1}=1$ and $\mathrm{n}_{\mathrm{k} 2}=1$, respectively.

The last step of the system identification procedure is the validation of the estimated model. After estimating, the model should be validated to determine whether the model can reproduce system behavior by estimating within acceptable bounds.

The selection of model structure and their orders is the main purpose. The selection of model structure depends on nonlinear effects in the system, system properties and prior knowledge of the system. The second purpose is selection of the model orders. The model orders were determined by some tests before and after estimation. In this paper, the second approach or tests after estimation is used. After estimation the best model by using the series of experimental data, another series of data is used for validating. In fact, another input data is given to the system and the model and their outputs are compared. The model is validated using a new data set, this process is called crossvalidation. In other words, by using the HammersteinWiener model (the best model) and the new input signals, $\mathrm{T}_{\mathrm{A}}$ and $\mathrm{T}_{\mathrm{B}}$ and comparing new estimated output, $h_{c}$, with the measured outputs. Results are shown in Table 4. According to Table 4, the Hammerstein-Wiener model estimates the thermal contact conductance with high accuracy and has an agreement with results of actual output of experiment.

\section{CONCLUSION}

The system identification method is an excellent method to estimate the heat transfer across the contact surfaces or thermal contact conductance with high accuracy. In this method, using the calculated transfer function and knowing the temperatures of specimens, the thermal contact conductance is estimated. One of the advantages of this method is that no prior information of the variation of the unknown quantities is needed since the solution automatically determines the functional forms over a specified domain. The most common nonlinear block-box parametric models, Hammerstein-Wiener and Nonlinear ARX, are examined.

This method can be utilized for the estimation of thermal contact conductance, which is extremely difficult to measure. By using the calculated transfer function, a computational model can be created. By assigning the temperatures of specimens as inputs, the heat transfer across contact surfaces can be estimated. The ultimate results are shown that the HammersteinWiener models have the great ability to control heat flux through contacting surfaces.

Therefore, this method can be used efficiently for estimating online heat flux across contacting surfaces especially in thermal contact between exhaust valve and its seat of internal combustion engines.

\section{REFERENCES}

1. Paradis, I., J.R. Wagner and E.E. Marotta, 2002. Thermal periodic contact of exhaust valves in spark ignition air-cooled engines. J. Thermophys. Heat Transfer, $\quad$ 16: 356-365. http://pdf.aiaa.org/jaPreview/JTHT/2002/PVJAIM P6712.pdf

2. Shojaefard, M.H., A.R. Noorpoor, M. Ghaffarpour and F. Mohammadi, 2007. Analysis heat flow between seat and valve of ICE. Am. J. Applied Sci., 4: 700-708. http://www.scipub.org/fulltext/ ajas/ajas49700-708.pdf

3. Howard, J.R., 1976. An experimental study of heat transfer through periodically contacting surfaces. Int. J. Heat Mass Transfer, 9: 367-372. DOI: 10.1016/0017-9310(76)90092-2.

http://www.sciencedirect.com/science?_ob=Article URL\&_udi=B6V3H-

$47 \mathrm{YSB} 7 \mathrm{FNN} \&$ user $=10 \& \mathrm{rdoc}=1 \&$ $\mathrm{fmt}=\& \_$orig $=$search\&_sort $=\mathrm{d} \&$ view $=$ c\&_version $=$ $1 \&$ urlVersion $=0 \&$ userid $=10 \& \mathrm{md} 5=\mathrm{ef} 0 \mathrm{a} 056 \mathrm{cc} 3 \mathrm{f}$ $7 \mathrm{bd} 45 \mathrm{cbb} 18 \mathrm{edb} 120 \overline{1} \mathrm{bfe} 6$

4. Flach, G.P. and M.N. Ozisik, 1988. Inverse heat conduction problem of periodically contacting surfaces. J. Heat Transfer, 110: 821-829. http://adsabs.harvard.edu/abs/1988ATJHT.110..82 $1 \mathrm{~F}$

5. Vick, B. and M.N. Ozisik, 1981. quasi-steady state temperature distribution in periodically contacting finite regions. J. Heat Transfer, 103: 739-744. http://www.me.vt.edu/MENewSite/Faculty/vick/vi ck.php. 
6. Moses, W.M. and R.R. Johnson, 1989. Experimental results for the quasi-steady heat transfer through periodically contacting surfaces. J. Thermophys. Heat Transfer, 3: 474-476. http://pdf.aiaa.org/preview/1987/PV1987_1608.pdf

7. Moses, W.M. and R.R. Johnson, 1988. Experimental study of the transient heat transfer across periodically contacting surfaces. J. Thermophys. Heat Transfer, 2: 37-42. http://pdf.aiaa.org/jaPreview/JTHT/1988/PVJAPR E59.pdf

8. Moses, W.M. and N.C. Dodd, 1990. Heat transfer across aluminum/stainless-steel surfaces in periodic contact. J. Thermophys. Heat Transfer, 4: 396-398. http://pdf.aiaa.org/preview/1988/PV1988_2646.pdf

9. Huang, C.H. and T.M. Ju, 1995. An inverse problem of simultaneously estimating contact conductance and heat transfer coefficient of exhaust gases between engine's exhaust valve and seat. Int. J. Numer. Methods Eng., 38: 735-754. http://www3.interscience.wiley.com/journal/11054 8573/abstract?CRETRY $=1 \&$ SRETRY $=0$

10. Couedel, D., F. Danes and J.P. Bardon, 1991. Experimental study and analysis of heat transfer in a valve-seat periodic contact in an internal combustion engine. ASME/HTD, 182: 59-66. http://iusti.polytech.univ-

mrs.fr/JITH2005/Communications PresenteesJITH 2005/Theme\%201_Presentees_Web/Communicati on_Azzouz\%20\&\%20al.pdf
11. Ljung, L., 1999. System Identification: Theory for the User. 2nd Edn. Prentice Hall PRT, New Jersey, USA, ISBN: 0-13-656695-2. http://www.control.isy.liu.se/ ljung/sysid/

12. Nelles, O., 2001. Nonlinear System Identification. 1st Edn. Springer-Verlag, Berlin Heidelberg, Germany, ISBN: 978-3-540-67369-9. http://www.springer.com/engineering/book/978-3540-67369-9

13. Ljung, L., 2007. MATLAB 7-System Identification Toolbox-User's Guide. The MathWorks, Inc. Massachusetts, USA. http://www.mathworks.com /access/helpdesk/help/toolbox/ident/ident_product_ page.html

14. Zhu, Y., 2001. Multivariable System Identification for Process Control. Pergamon. 1st Edn. Pergamon, Elsevier Science Ltd. Oxford, UK, ISBN: 0-08043985-3.

http://www.elsevier.com/wps/find/bookdescription. cws_home/622347/description\#description 